\title{
Balance Assessment in Deaf Children and Teenagers Prior to and Post Capoeira Practice through the Berg Balance Scale
}

Rubianne Lima

\begin{abstract}
Introduction: Hearing loss changes the functionality and body structure a disability that limits activity and restricts the participation of the individual in situations of daily life. It is believed that capoeira can help people with visual disabilities to minimize these deficits. BSE is a low specificity scale that evaluates objectively and functionally aspects of balance and risk of falls in the elderly and children, including the effect of environment on balance function. Objective: The objective of the research is to analyze deaf children and adolescents prior to and post-practice of capoeira using the Berg Balance Scale (BBS). Methods: Quantitative, clinical and observational studies. Twenty five deaf children between 10 and 16 years old of both genders were assessed. BBS was applied in two stages: before starting capoeira and after 6 months of training. The one-hour classes were held once a week for quantitative evaluation purposes. The subjects were divided and evaluated in two groups (10-13 years old and 14-16 years old). Results: There was a significant statistical difference in BBS scores. The general group and the group of $10-13$ years old $(p=0.0251)$ showed an increase in scores after practicing capoeira $(p=0.0039)$. There were no statistically significant differences in the group from 14 to 16 years of age $(p=0.0504)$. Conclusion: Using the Berg Balance Scale, it was possible to observe an improvement in the balance of the group of children and adolescents who practiced capoeira, and consequently, a decrease in the risk of falling.
\end{abstract}

Keywords: postural balance, deafness, berg balance scale. 


\section{INTRODUCTION}

Because we are structured to receive continuous feedback through the sense of hearing, hearing loss can be an obstacle that interferes with our daily life. Hearing loss changes the body's functionality and structure. This disability limits activities and restricts the participation of a person in everyday situations. Ear diseases such as infectious processes caused by bacteria and viruses can have cochlear involvement. This can result in hearing loss and vestibular alteration leading to a loss in physical balance ${ }^{1}$. Maintaining balance depends on the anatomical and functional integrity of the vestibular apparatus as well as the correlation between the visual, auditory, proprioceptive, muscular-skeletal and nervous centers ${ }^{2}$.

Over the past few years, the art of capoeira has been inserted in many different institutional spaces in Brazilian cities and several other countries ${ }^{3}$. It is currently recognized as a part of Brazilian Cultural Heritage, and is a mix of a fight-game-dance practiced to the sound of musical instruments (berimbau, tambourine and conga), claps and songs ${ }^{3}$. Capoeira is an exceptional self-defense and fitness system ${ }^{3}$. Capoeira, as well as physical education, does not present any difference in content when adapted to people with special needs. It uses techniques, methods and forms of organization that can be applied to these people to ${ }^{4}$.

It is believed that capoeira may assist the physical balance of people with hearing loss, as it assisted visually impaired individuals to minimize such deficits. The reason being that balance is one of the qualities worked on in capoeira $^{5,6}$.

BBS is a low specificity scale that evaluates the different aspects of balance and risk of falls in the elderly and children in objective and functional ways. This includes the effect of the environment on the sense of balance ${ }^{7}$. The maximum score a person can receive when executing the various body positions is 56 points. The scale was developed in order to monitor the patient's state of balance, the course of disease, and the prediction of falls. It was also developed to select patients for the rehabilitation process, and the their response to treatment ${ }^{8}$. This study aims to evaluate deaf children and adolescents before and after the capoeira practice using BBS as a tool.

\section{METHODS}

This an action research study in which empirical research is designed and carried out in close association with an action or collective problem solving. Researchers and participants are involved in a cooperative or participative way ${ }^{9}$. This clinical study was quantitative and observational. The study was submitted to the Institutional Ethics Committee and was initiated after approval. Twenty five participants aged 10 to 16 years, 11 male and 14 female, were randomly and non-probabilistically selected.
Participants who had profound neurosensory hearing loss were included. Participants with cochlear implants, visual, motor or neurological changes were excluded. Those who did not want to participate in the study as well as those who for some reason did not participate in more than three classes were also excluded. Participants were evaluated through the Berg Balance Scale (BBS) in two stages by the same examiner. One-hour capoeira classes were adapted for the hearing impaired and held in a private room every week for a period of 6 months (Chart 1). A nonparametric Wilcoxon test was performed for statistical analysis.

The BBS consists of 14 tasks involving static and dynamic balance common in everyday life. It assesses postural control, including stable and anticipatory postures. These tasks require different forces, dynamic balance and flexibility. It also assesses how one moves from a seated to a standing position, how one remains standing without support and rotates 360 degrees. Each item has an ordinal scale of five alternatives ranging from 0 to 4 points. The total score is 56 points and ranks performance from 0 (unable to perform) to 4 points (normal). The sum of all scores results in an overall score that is categorized as follows: $41-56$ indicates a low risk of falls; $21-40$ means the risk of falling is moderate; below 20 indicates the risk of falling is high ${ }^{10,11}$ (Chart 1).

The scoring of this scale is defined by three factors:

a) The duration for which a position can be maintained.

b) The distance one is able to reach out in front of the body.

c) The time to complete the task.

Furthermore, the tasks should be performed dressed and barefoot, and while wearing any necessary glasses and/or hearing aids. Each task must be carried out exactly as described, and the patient must be instructed to maintain a certain position for a given time, thus more points are reduced progressively if the time or distance required are not achieved ${ }^{10,11}$.

Participants who wore hearing aids during the tests had total communication ability (sign language and lip reading). 6 months after the test, during the twenty-fourth class, the BBS was applied to 25 students in the same initial situation.

The movements used to practice capoeira with children were (Figures a-f):

a) Dodge: it is a defence movement in capoeira. Its objective is to avoid a blow without touching the opponent.

b) "Ginga": it is a movement of body dexterity. All other capoeira moves evolve from this basic move.

c) "Au": It is a moving step of the capoeira artist in the circle. It allows the person to get closer or farther 
Chart 1: Berg balance scale.

1) Sitting to standing

Instructions: Please stand up. Try not to use your hands as support.

\section{2) Standing position unsupported}

Instructions: Please remain standing for 2 minutes without using anything as support

If the patient is able to remain in standing position for 2 minutes without any support, give him number 3 total of points. Keep item number 4.

3) Sitting position with back unsupported, but feet supported on the floor or on a stool.

Instructions: Please, remain seated without any support on your back. Keep your arms folded for 2 minutes.

\section{4) Standing to sitting}

Instructions: Please, sit down

\section{5) Transfers}

Instructions: Set up the chairs perpendicularly or across from each other for pivot transfer. Ask patient to transfer himself from a chair with arms to another one without arms, and vice versa.

6) Standing unsupported with closed eyes Instructions: Please, close your eyes and stand still for 10 seconds

7) Standing unsupported with feet together Instructions: Put your feet together without any support

(4) able to stand up without hands and to stabilize independently

(3) able to stand up with hands independently

(2) able to stand up hands after several attempts

(1) needs minimum help to stand up or to stabilize

(0) needs moderate or maximum help to stand up

(4) able to stand safely for 2 minutes

(3) able to stand position for 2 minutes under supervision

(2) able to remain in standing position for 30 seconds without support

(1) needs several attempts to remain in standing position for 30 seconds without support

(0) unable to remain in standing position for 30 seconds without any support

(4) able to confidently and firmly remain seated for 2 minutes

(3) able to remain seated for 2 minutes under supervision

(2) able to remain seated for 30 seconds

(1) able to remain seated for 10 seconds

(0) unable to remain seated without support for 10 seconds

(4) sits safely with minimum use of hands

(3) controls descend using hands

(2) uses back of legs on chair

(1) sits independently but uncontrolled

(0) needs assistance to sit

(4) transfers safely with minor use of hands

(3) transfers safely with use of hands

(2) transfers with verbal directions and supervision

(1) needs the help from one person

(0) needs help to sit down

(4) able to stand still safely for 10 seconds

(3) able to stand still safely for 10 seconds under supervision

(2) able to stand still for 3 seconds

(1) unable to keep eyes closed for 3 seconds but able to stand still

(0) needs help not to fall down

(4) able to place feet together independently and stand for 1 minute safely

(3) able to place feet together independently and stand for 1 minute under supervision

(2) able to place feet together independently and stand for 30 seconds

(1) needs help positioning feet together but able to hold it for 15 seconds

(0) needs help positioning feet together but is unable to hold position for 15 seconds

8) Reaching forward with outstretched arms while standing Instructions: Raise your arm to 90 degrees. Stretch your fingers and try to reach forward the most you can

(4) able to reach forward safely $>25$ centimeter

(3) able to reach forward safely $>12.5$ centimeters

(2) able to reach forward safely 5 centimeters

(1) able to reach forward, but requires supervision

(0) loses balance or needs support

(4) looks behind from both sides with good weight distribution

10) Turning around to look behind over right and left shoulders while standing

Instructions: Turn around to directly look behind you. Look over your left shoulder without taking off feet from the ground. Do the same with right shoulder.

(3) looks behind from one side only, the opposite side shows poorer weight distribution

(2) turns sideways only but keeps balance

(1) needs supervision to turn

(0) needs help not to lose balance or fall down

\section{1) Turning 360 degrees}

Instructions: Turn completely in a full circle. Pause. Turn completely in a full circle but on the opposite side.

\begin{tabular}{|c|c|}
\hline $\begin{array}{l}\text { 12) Placing alternate foot on step or stool while standing } \\
\text { unsupported } \\
\text { Instructions: Put each foot alternately on step or stool while } \\
\text { standing unsupported. Keep until each foot has touched the } \\
\text { step or stool four times. }\end{array}$ & $\begin{array}{l}\text { (4) able to stand independently and safely, performing } 8 \text { movements in } 20 \text { seconds } \\
\text { (3) able to stand independently and perform } 8 \text { movements in }>20 \text { seconds } \\
\text { (2) able to complete } 4 \text { movements with no help } \\
\text { (1) able to complete }>2 \text { movements with minor help } \\
\text { (0) unable to try or needs help to prevent fall }\end{array}$ \\
\hline $\begin{array}{l}\text { 13) Standing unsupported with one foot in front } \\
\text { Instructions: Place one foo directly in front of the other. If } \\
\text { you are unable to do it, place foot a bit more further than the } \\
\text { other one and slightly sideways. }\end{array}$ & $\begin{array}{l}\text { (4) able to place foot directly in front of the other independently, and hold the } \\
\text { position for } 30 \text { seconds } \\
\text { (3) able to place foot a bit in front of the other and slightly sideways independently, } \\
\text { and holds the position for } 30 \text { seconds } \\
\text { (2) able to take a small step independently and hold the position for } 30 \text { seconds } \\
\text { (1) needs help to take the step, but is able to hold the position for } 15 \text { seconds } \\
\text { (0) loses balance when trying to take a step or stand }\end{array}$ \\
\hline $\begin{array}{l}\text { 14) Standing on one leg } \\
\text { Instructions: Stand on one leg the most you can without } \\
\text { support }\end{array}$ & $\begin{array}{l}\text { (4) able to lift one leg independently and hold the position for }>10 \text { seconds } \\
\text { (3) able to lift one leg independently and hold the position for } 5-10 \text { seconds } \\
\text { (2) able to lift one leg independently and hold the position for } \geq 3 \text { seconds } \\
\text { (1) tries to lift one leg but is unable to hold the position for } 3 \text { seconds, but remains } \\
\text { standing independently } \\
\text { (0) unable to try or needs help to prevent fall }\end{array}$ \\
\hline
\end{tabular}

12) Placing alternate foot on step or stool while standing unsupported

tanding unsupported. Keep until each fc step or stool four times.

13) Standing unsupported with one foot in front

(4) able to turn 360 degrees safely in 4 seconds or less

(3) able to turn 360 degrees safely to one side only in 4 seconds or less

(2) able to turn 360 degrees safely, but slowly

(1) needs supervision or verbal directions

(0) needs help while turning

(4) able to stand independently and safely, performing 8 movements in 20 seconds

(3) able to stand independently and perform 8 movements in $>20$ seconds

(2) able to complete 4 movements with no help

able to complete $>2$ movements with minor help

(3) able to place foot a bit in front of the other and slightly sideways independently,

and holds the position for 30 seconds

(1) take a small step independently and

(4) able to lift one leg independently and hold the position for $>10$ seconds

(3) able to lift one leg independently and hold the position for 5-10 seconds

standing independently

0) unable to try or needs help to prevent fall 


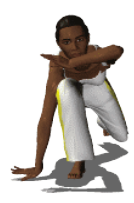

a)

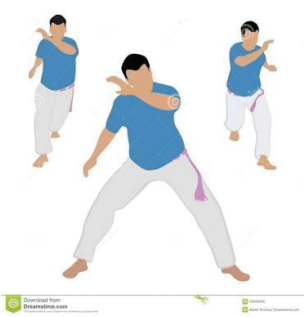

b)
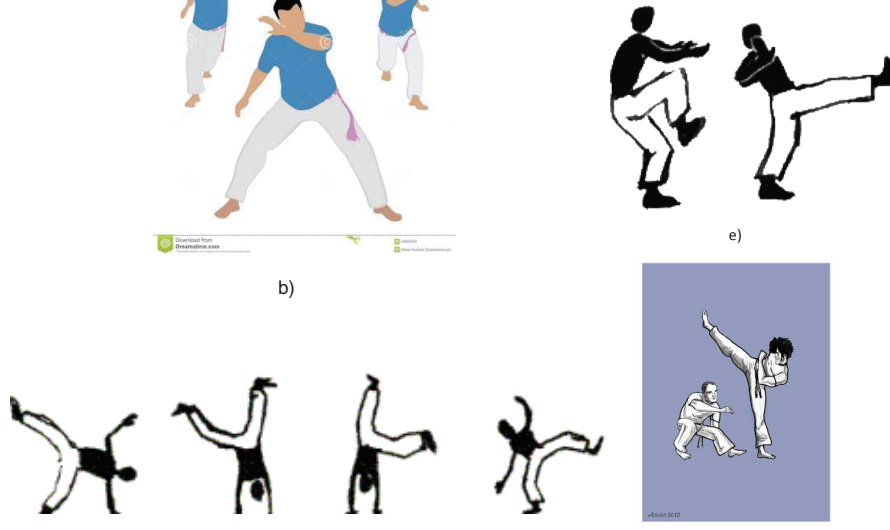

Figures (a-f). The movements used to practice capoeira with children.

away from the opponent, setting up attacks and executing defences.

d) "Bananeira": The player's arms must be kept straight and stretched, his head pointed toward the ground. Some strength is required during a natural movement and when moving one leg forward onto the other one which is moving. This allows the player to create a balance system using the leg in movement, wherein gravity assists the hand stop rather than restricting it.

e) Blessing: In order to perform this movement, the player needs to lift the leg that lies behind in the Ginga and to pull it towards himself. In one swift motion, he needs to push the leg against the opponent's chest, trying to hit the opponent with his heel.

f) Hammer: the blow is struck in three stages: it starts with one leg curled sideways; the foot can strike using the tip or the sole laterally to the body turn in order to hit the opponent from the front. The return movement happens in the same way and during the movement the foot strikes and bounces back.

For better analysis of statistical data, the participant's age ranged from 10 to 16 . They were divided into two groups:

a) 10 to 13 years old

b) 14 to 16 years old.

\section{RESULTS}

One student was excluded for missing more than three classes during 6-month study.

\section{Analysis of berg balance scale in the 10-16 age group}

In this age group, the BBS average before the capoeira classes was 52. It was 54.5 after 6 months of capoeira class. Statistically, there was a significant difference $(p=0.0039)$ with the increase in scores after capoeira classes (Graph 1).

Analysis of berg balance scale in the 10-13 age group

Before capoeira classes, the BBS average of 10-13 age group was 51.2. It was 54.1 after 6 months of capoeira class. Statistically, there was a significant difference $(p=$ 0.0251 ) with the increase in scores after capoeira classes (Graph 2).

Analysis of berg balance scale in the 14-16 age group

Before capoeira classes, the BBS average of 1416 age group was 51.2. It was 54.85 after 6 months of capoeira class. Statistically, there was no significant difference $(p=0.0504)$ with the increase in scores after capoeira classes (Graph 3).

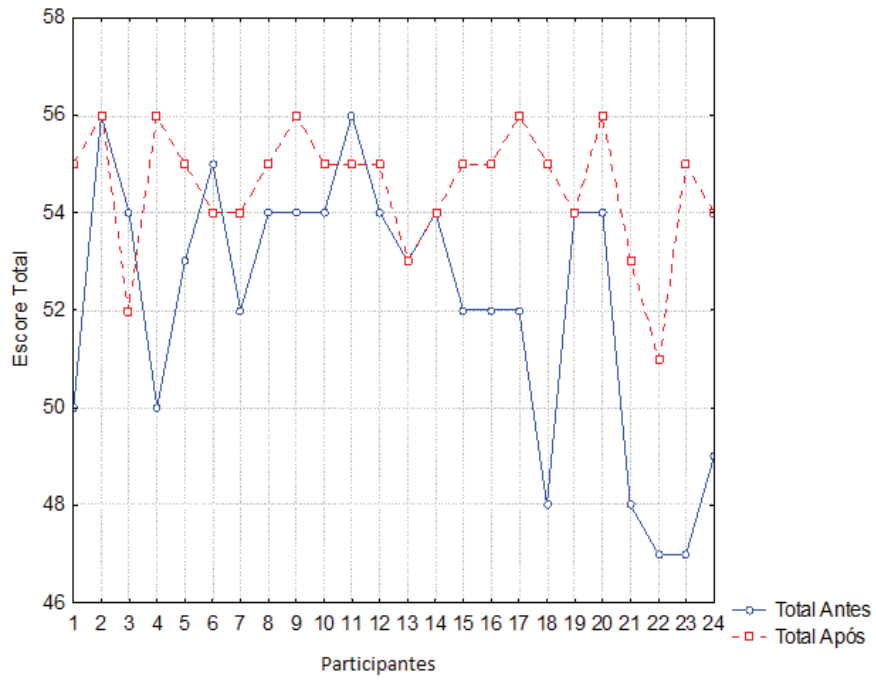

Graph 1. Comparison among participants total scores prior to and postpractice of capoeira, 10-16 age group.

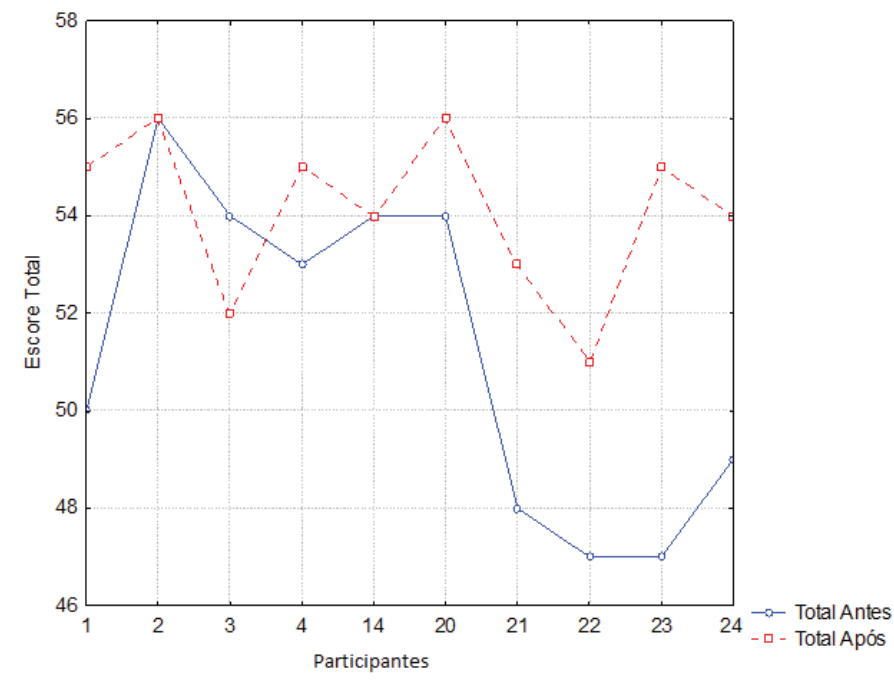

Graph 2. Comparison among participants' total scores prior to and post-practice of capoeira, $10-13$ age group. 


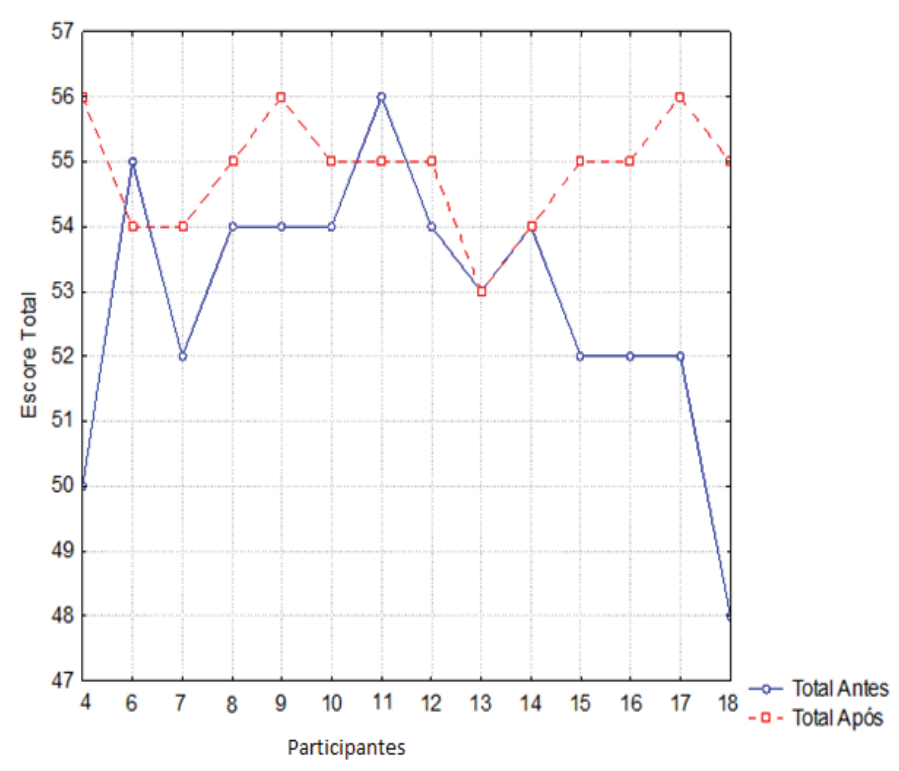

Graph 3. Comparison among participants' total scores prior to and post-practice of capoeira, 14-16 age group.

\section{DISCUSSION}

In general, this sport improves overall body awareness as well as improving: intellectual and moral development, behavior, social skills, and emotional stability. It also decreases stress and reenergizes individuals or groups ${ }^{12}$.

Inclusion is seen as agood result since, "it represents a very concrete and manageable step that can be taken in our educational systems. It ensures that all participants learn that belonging is a right and not a privileged status to beachieved"13. Among the possibilities in applying capoeira to the world through children's physical education, we highlight some phases that represent real and concrete alternatives in educational intervention with children who are 0-6 years old. These alternatives are optimized from children's communication, contextualization and pedagogical intentionality. Musicality, movement, ritual and interpersonal relationships are a few examples. In practical terms, the potential to construct social pedagogy establishes critical ownership for learners and educators. Capoeira can easily serve both the "revolution" and "alienated conformity."

The pace, or rhythm, is potentially exploited in capoeira's musicality and has the power to generate impulse and movement in space. It develops motor skills intertwining them with sensory perception. In addition to inducing affective states, it contributes to some acquisitions such as language, reading, writing and math/ logic ${ }^{12}$. Capoeira in early childhood education is related to the playfulness of the moves that will be experienced through games that children play in daily life. In this way, the child learns capoeira and its fundamentals through activities that help his motor coordination, visual field, creativity, self-esteem, and automation of movements. It educates children in the management of time and space within a given movement. The result is a more outgoing and confident child ${ }^{14}$.

The musical and movement association allows the child to feel a rhythmic identity, connecting body movements and music. When the children sing these songs, linking them to their own breathing, it is not aggressive and can take a musical theme. The children must then adapt themselves to sensorial motor synchronization exercises ${ }^{15}$.

Nowadays, we can notice a greater demand from the deaf community for the practice of capoeira because of the body development that it provides. It is known that a hearing-disabled person requires specific methods that take his learning necessities into consideration. The learner starts to comprehend and interact with the world through visual experiences, expressing his culture, especially when using sign language, (Note: Brazilian Sign Language-LIBRAS-was established under Federal Law No. 10.436/2002, and regularized in December 2005, by Federal Decree 5.626) ${ }^{16}$.

We recognize the specific needs of the deaf person as a starting point to systematize the practice. We make use of the theory in a socio-cultural perspective in order to achieve success in capoeira classes. The work always includes them in the socio-educational process, being aware of the need for urgent change in the way they perceive the world ${ }^{17}$.

Looking at capoeira as a path to health, socialization and intellectual work, it is always associated with an exercise focused on the teacher that is developing the learning technique. The interaction of capoeira with deaf people is extremely important for a harmonious environment because this sport works physical-motor, balance cognition and socialization skills. Studies correlate visual impairment with changes in balance function. This is because body control happens due to the integration of several structures that comprise a control system, called the balance system ${ }^{18}$. Thus, the proposal to quantitatively describe the skill of functional balance was to show that capoeira has the ability to develop the fields of learning by observing three important aspects for balance: psychomotor, affective, and cognitive.

The goal of this study was not to evaluate the individual student's score, but to overall average scores for groups of students. This was a non-parametric view of the before and after for the practice of capoeira in a self-controlled manner. We considered the peculiarity of each deaf child, regarding his somatosensory experience and the degree of stimulation. In this study, we observed a significant difference in the individual scores prior to and post capoeira practice for children with profound hearing loss, using the Berg Balance Scale for analysis. The analysis demonstrated significant improvement, and showed that capoeira can significantly decrease falls and increase balance in the deaf children that were evaluated. 


\section{CONCLUSION}

After this research and the practice of capoeira by deaf children, an improvement was noted in balance and there was a decrease in the risk of falling. Analysis was carried out using the Berg Balance Scale.

\section{REFERENCES}

1. Russo ICP, Santos TMM. Practice of clinical audiology. 8th edn. Cortez; 2011.

2. Azevedo MG, Samelli AG. Comparative study of the balance of deaf and hearing children. Rev CEFAC. 2009;11(Supl. 1):85-91.

3. Falcão JLC. The game of capoeira in game. Rev Bras Science. 2006;27:59-74.

4. Neves GN, Frasson AC. Physical education adapted to the visually impaired. In: Physical education and sports symposium in the south of Brazil (Fontoura). 2003;15:291.

5. Matos JN, Menezes FS. Capoeira for the visually impaired: Comparing the balance between practitioners and non-capoeira practitioners. Rev Bras Science Sport. 2012;34:81-93.

6. Souza SAR, Oliveira, AAB. Structuring of Capoeira as Physical Education Content in Elementary and Middle School. J Phys Edu. 2001;12:43-50

7. Marinho Junior C, Cavenagui S, Marino LHC. Measurement scales and physiotherapeutic modalities in the rehabilitation of patients with deficit balance. Arq Ciênc Health. 2011;18(1):44-9.

8. Halssa, KE, Brovold T, Graver V, Sandvik I, Bergland A. Assessments of interrater reliability and internal consistency of the Norwegian version of the Berg Balance Scale. Arch Phys Med Rehabil. 2007;88(1):94-8.

9. Thiollent M. Action Research Methodology. 7th edn. Cortez; 1996.

10. Whitney S, Weisley D, Furman J. Concurrent validity of the berg balance scale and the dynamic gait index in people with vestibular dysfunction. Physiother Res Int. 2003;8:178-86.

11. Miyamoto LJ, Junior IL, Berg KO, Ramos LR, Natour J. Brazilian version of the berg balance scale. Braz $J$ Med Biol Res. 2004;37:1411-21.

12. Silva JAB. Importance of Capoeira in the development of body culture in children's education [monograph]. Salvador: State University of Bahia, School Physical Education Teaching; 2003. p.1-41.

13. Bonfim GCS. The practice of capoeira in physical education and its contribution to the application of law 10.639 in the school environment: Capoeira as a means of social inclusion and citizenship. Annals of the III Northeast Congress of Sports Sciences. Fortaleza Brazil; 2010.

14. Sassaki RK. Building a society for all. Rio de Janeiro, Brazil: WVA Publisher;1997.

15. Boulch L. Psychomotor development: From birth up to 6 years. Porto Alegre. Medical Arts; 1992.

16. Freitas JL. Capoeira in Physical Education: how to teach? Curitiba: Progressive Publisher; 2007.

17. Ferreira ACL, Castro AS. The praxis educational partner for development human in the perspective of citizenship. proceedings of the 24th symposium of the association national policy and administration of education. Espírito Santo Brazil; 2009.

18. Matos JB, Menezes FS. Capoeira for visually impaired: Comparison of between practitioners and non-capoeira practitioners. Rev Bras Science Sport. 2012;34(1):81-93. 